\title{
Crohn's disease and colorectal cancer
}

\author{
C D Gillen, H A Andrews, P Prior, R N Allan
}

\begin{abstract}
The colorectal cancer risk in Crohn's disease eliminating all known biases was assessed in a cohort of 281 patients with Crohn's disease who resided in the West Midlands at the time of diagnosis, and were first seen within five years of onset of symptoms between 19451975. All patients were 15 years of age or more at onset and were followed up from 12-35 years (total 5213 person years at risk (PYR)). The colorectal cancer risk in the series compared with the risk in the general population was computed by applying sex and age specific PYRs to the date of death or end of the study period 31 December 1991. There were six colonic and two rectal cancers. Six of the eight colorectal cancers were diagnosed 20 or more years after the onset of Crohn's disease. The relvative risk (RR) of colorectal cancer for the series as a whole was $3.4(p<0.001)$, with a fivefold excess in the colon, but no significant excess in the rectum. Patients with extensive colitis showed an 18-fold increase in risk $(\mathbf{R R}=18 \cdot 2, \mathbf{p}<0.001)$, which decreased with increasing age at onset. This study shows that there is a statistical excess risk of developing colorectal cancer in patients who develop their Crohn's disease at a young age of onset (less than 30 years of age).

(Gut 1994; 35: 651-655)
\end{abstract}

Early studies of individual case reports and small series of patients with Crohn's disease who developed colorectal cancer have been summarised by Lewis et al, 1980.' Three larger series of 10,14 , and 25 patients respectively have been described recently..$^{2-4}$

The first statistical estimate of colorectal cancer complicating Crohn's disease was reported by Weedon et al..$^{5}$ Twelve patients with cancer (seven of the large intestine, one rectum, one jejunum, and three elsewhere) were identified among 449 patients in a highly selected group of patients who were all less than 21 years of age at the symptomatic onset (mean age 14.9 years) of their Crohn's disease. The observed colorectal cancer risk in all their patients with Crohn's disease was 20 times that expected in the general population. The risk was more noticeable (but not quantified) when confined to the 356 patients with colonic involvement as all eight colorectal cancers occurred in this group. ${ }^{5}$

Greenstein $e t a l^{67}$ estimated the cancer risk of 579 hospital based Crohn's disease patients admitted to Mount Sinai Hospital between 1960-1976. Seven colorectal cancers among 327 patients with Crohn's colitis or ileocolitis were identified; there was a $6 \cdot 9$-fold excess risk when compared with the general population. The selection biases inherent in a hospital series were recognised by the authors as a limitation of this study.

In a population based statistical study from Uppsala, Sweden, 12 colorectal cancers were diagnosed among 1655 patients with Crohn's disease followed up between 1965 and 1983. The relative risk for developing colorectal cancer among patients with colonic Crohn's disease was $5 \cdot 6$. There was a higher relative risk in patients with colonic disease diagnosed before 30 years of age (relative risk 20.9) than those diagnosed at older ages (relative risk $2 \cdot 2$ ). ${ }^{8}$

Three statistical studies have found no association between colorectal cancer and Crohn's disease. Binder et $a l,{ }^{9}$ found no excess gastrointestinal cancers among 185 patients followed up between 1960-1978. Only 118 patients, however, had large intestinal involvement and the follow up was comparatively short (mean 5.5 years).

Kvist et $a l,{ }^{10}$ found no significant excess risk of developing cancer of the gastrointestinal tract when compared with the general population matched by age, sex, and duration of disease among 473 patients with Crohn's disease followed up between 1964-1983, of whom 350 had some large intestinal involvement and 149 extensive colonic disease. Most, however, had had extensive large bowel resection, either panproctocolectomy (55) or colectomy (71) thus eliminating the cancer risk.

Gollop et $a l,{ }^{11}$ found no evidence of excess cancer risk in the gastrointestinal tract in 103 patients with Crohn's disease followed up between 1943-1982, but only 15 patients had been diagnosed before 1962 .

In the three studies, the lack of association could be ascribed either to the comparatively small number of patients studied, the short duration of follow up or the large proportion of patients receiving colectomy.

In an earlier study of our own unselected hospital based series, nine colorectal cancers were identified in an adult series of 513 patients with Crohn's disease followed up between 1944 1976 (mean follow up of 14.5 years). There was a fourfold overall excess risk of developing colorectal cancer. The excess risk was $12 \cdot 8$-fold in patients with extensive colitis and 23.8-fold after correction for colectomy and panproctocolectomy. ${ }^{12}$

We have recently calculated the colorectal cancer risk in ulcerative colitis after identifying and either eliminating or correcting all the known selection biases inherent in a hospital series. This study showed that if these biases were identified and corrected, an equally accurate estimate of the colorectal cancer risk could be determined in a hospital based series of patients with ulcerative colitis, as in a population based study. ${ }^{13}$ 
In this study we have for the first time calculated the colorectal cancer risk in Crohn's disease in a hospital series, after correction of all the known selection biases, so that this estimate could be applied to unselected series elsewhere. We have also examined the effects of age at onset, extent, and duration of colitis on the colorectal cancer risk.

\section{Methods}

DEFINITION OF THE COHORT

Population based studies are difficult to carry out in England, because the hospitals providing a major referral service for inflammatory bowel disease patients are situated in the larger cities in areas of high population density, with many district general hospitals serving the population and a large population movement in and out of the area. In these circumstances an alternative approach to population based studies is to define a cohort of patients, representative of all patients diagnosed with Crohn's disease from the general population in which to study the cancer risk.

In this study we recruited only patients from a defined geographical area in the West Midlands who were primary referrals to identified

TABLE I Crohn's disease: distribution of series by age and sex at onset

\begin{tabular}{lccc}
\hline Age group & Men & Women & Total \\
\hline $15-20$ & 34 & 23 & 57 \\
$20-29$ & 48 & 49 & 97 \\
$30-39$ & 24 & 34 & 58 \\
$40-49$ & 15 & 12 & 27 \\
$50-59$ & 11 & 11 & 22 \\
$60+$ & 10 & 10 & 20 \\
Total & 142 & 139 & 281 \\
\hline
\end{tabular}

TABLE II Crohn's disease: maximum extent of disease $(n=281)$

\begin{tabular}{lr}
\hline Site & \multicolumn{1}{c}{$n(\%)$} \\
\hline Small bowel only & $67(23 \cdot 8)$ \\
Large bowel only & $73(26 \cdot 0)$ \\
Small and large bowel & $141(50 \cdot 2)$ \\
\hline
\end{tabular}

TABLE III Crohn's disease: complete excision of colon or rectum in patients with large bowel involvement $(n=214)$

\begin{tabular}{llrl}
\hline \multicolumn{3}{l}{ Extensive colitis } & \\
\cline { 2 - 3 } & $N o(n(\%))$ & $Y e s(n(\%))$ & $\operatorname{Total}(n(\%))$ \\
\hline Colon excised & & & \\
$\quad$ No & $89(41 \cdot 6)$ & $39(18 \cdot 2)$ & $128(59 \cdot 8)$ \\
$\quad$ Yes & $-\overline{86}(40 \cdot 2)$ & $86(40 \cdot 2)$ \\
$\quad$ Total & $89(41 \cdot 6)$ & $125(58 \cdot 4)$ & $214(100 \cdot 0)$ \\
Rectum excised & $89(41 \cdot 6)$ & $91(42 \cdot 5)$ & $180(84 \cdot 1)$ \\
$\quad$ No & - & $34(15 \cdot 9)$ & $34(15 \cdot 9)$ \\
Yes & $89(41 \cdot 6)$ & $125(58 \cdot 4)$ & $214(100 \cdot 0)$ \\
\hline
\end{tabular}

TABLE IV Crohn's disease: person, colon, and rectum years at risk (five + years from onset)

\begin{tabular}{llll}
\hline & $n$ & $P Y R$ & Mean \\
\hline All patients & 258 & 5213 & $20 \cdot 2$ \\
$\quad$ Total & 221 & 3884 & $17 \cdot 6$ \\
Colon & 248 & 4647 & $18 \cdot 7$ \\
Rectum & 116 & 2283 & $19 \cdot 7$ \\
Extensive colitis & 79 & 2165 & $12 \cdot 1$ \\
$\quad$ Total & 106 & 2296 & $16 \cdot 2$ \\
Colon & & \\
Rectum & & & \\
\hline PYR = patient years at risk. & &
\end{tabular}

$\mathrm{PYR}=$ patient years at risk. hospitals at or near the onset of their disease, thus eliminating secondary and tertiary referral biases in this otherwise specialist hospital series.

\section{ENTRY CRITERIA}

Patients were selected for this study from among those first seen at the General and Queen Elizabeth Hospitals, Birmingham between 1945-1975, provided that they were resident in the West Midlands region, were 15 or more years of age, and were within five years of symptomatic onset of Crohn's disease when first seen at the index centre.

\section{DESCRIPTION OF THE SERIES}

A primary referral series of 281 patients was identified based on these criteria among more than 500 patients seen at the index centres by 1976. Table I shows the distribution by age and sex. Table II summarises an assessment of the maximum extent of Crohn's disease including the 214 patients with involvement of the large intestine. One hundred and twenty five patients had extensive colitis, of whom 96 patients (40\%) had been treated by total colectomy and in addition 34 (16\%) had had proctectomy (Table III). A total of 5213 patient years at risk (PYR) (mean 20.2 years from onset) was seen for all patients, but it can be seen that the mean PYRs were reduced by $38.6 \%$ of colon years at risk and by $17 \cdot 8 \%$ for rectum years at risk (Table IV).

\section{COMPUTATION}

The number of cancers expected to occur, on the basis of the cancer incidence rates for the West Midlands Region, was computed using the person years programme. ${ }^{14}$ The procedure applied sex, age, and site specific cancer incidence rates, derived from data from the West Midlands Regional Cancer Registry, to sex and age specific person years at risk. For cancer sites, other than large bowel, PYR were accumulated to date of death or to 31 December 1991 for survivors.

When computing expected numbers for colorectal cancers, PYR were truncated at the date when total colectomy or proctectomy, or both had been completed. The results for 'all sites of cancer' were then modified to allow for the effect of truncation on the estimates of expected numbers.

\section{STATISTICAL TESTING}

The relative risk of cancer (RR) is defined as the observed/expected number, the risk being relative to that of the general population. The significance of the difference between the RR and 1.0 was assessed by assuming that the observed number followed a Poisson distribution, with a mean equal to the expected number. Exact Poisson probabilities were computed for a one tailed significance test. The method of Rothman and Boice ${ }^{15}$ was used to obtain $95 \%$ confidence intervals $(95 \% \mathrm{CI})$ for the RRs. Estimates of cumulative risk of colorectal cancer were computed by the product limit method. 


\section{Results}

\section{COLORECTAL CANCERS}

The six colon cancers represent a highly significant fivefold excess when assessed against the expectation for the whole series. No significant excess was seen in the rectum, where only two cases were found, although they. represent a nearly twofold risk. The combined colorectal cancer risk is also shown (observed $=8$, expected $=2 \cdot 34, R R=3 \cdot 4, p<0.001)$ (Table V).

\section{EXTENSIVE COLITIS}

Colorectal cancers were found only in patients who had developed extensive colitis and for this group the overall risk was extremely high $(R R=$ $18 \cdot 2,95 \%$ CI $7 \cdot 8$ to $35 \cdot 8, \mathrm{p}<0 \cdot 001)$. The risk also fell with increasing age at onset. As might be expected, however, with these small numbers the $95 \% \mathrm{CI}$ are wide (Table VI).

Table VII gives details of the eight colorectal cancers. Six cancers occurred in the colon and two in the rectum; six of eight cancers were diagnosed 20 or more years after onset and were symptomatic at presentation while the two occurring at 12 years were asymptomatic and incidental findings at panproctocolectomy.

An estimate of cumulative risk in extensive colitis has been made but because the numbers are small, the CIs are wide. The estimate at 25

TABLE V Crohn's disease: cancer morbidity five+ years from onset of Crohn's disease (corrected for operation)

\begin{tabular}{|c|c|c|c|c|}
\hline \multirow[b]{2}{*}{ Site } & \multicolumn{2}{|l|}{ Cancers } & \multirow[b]{2}{*}{$R R$} & \multirow[b]{2}{*}{$95 \% C I$} \\
\hline & Observed & Expected & & \\
\hline $\begin{array}{l}\text { All sites } \\
\text { Colon } \\
\text { Rectum } \\
\text { Small bowel } \\
\text { Other }\end{array}$ & $\begin{array}{r}34 \\
6 \\
2 \\
2 \\
24\end{array}$ & $\begin{array}{r}23.01 \\
1.23 \\
1.11 \\
0.05 \\
20.62\end{array}$ & $\begin{array}{l}1 \cdot 5^{\star} \\
4 \cdot 9^{\star \star} \\
1 \cdot 8^{\star \star} \\
40 \cdot 0^{\star \star} \\
1 \cdot 7^{-1}\end{array}$ & $\begin{array}{l}1.0 \text { to } 22.1 \\
1.8 \text { to } 10.6 \\
0.2 \text { to } 6.5 \\
4.5 \text { to } 144.4 \\
0.7 \text { to } 1.7\end{array}$ \\
\hline Colon and rectum & 8 & $2 \cdot 34$ & $3 \cdot 4^{\star \star \star}$ & $1 \cdot 5-6 \cdot 7$ \\
\hline
\end{tabular}

${ }^{\star} \mathrm{p}<0.05 ;{ }^{\star \star} \mathrm{p}<0.01 ;{ }^{\star \star \star} \mathrm{p}<0.001 . \mathrm{RR}=$ relative risk.

TABLE VI Crohn's disease: cancer of the large bowel by age at onset of Crohn's disease (five+ years after onset, corrected for operation)

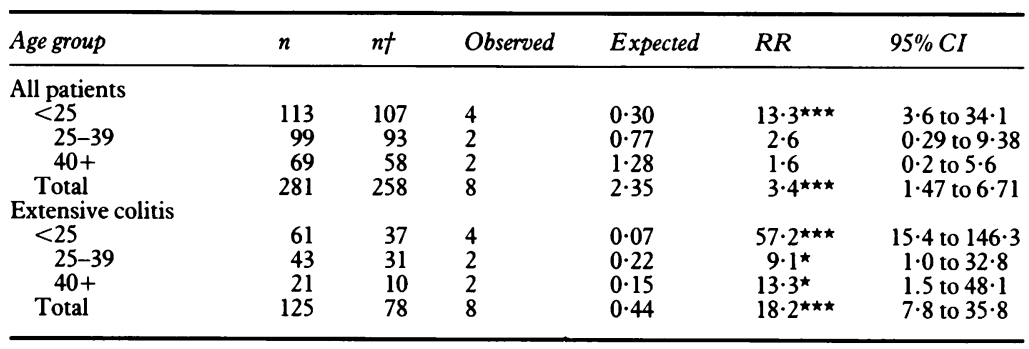

$\mathrm{RR}=$ relative risk; $\mathrm{n}=$ number at onset; $\mathrm{n} \dagger=$ number at five years from onset (number with colon intact for extensive colitis); ${ }^{\star} \mathrm{p}<0.05 ;{ }^{\star \star \star} \mathrm{p}<0.001$.

TABLE VII Colorectal cancers: clinical data

\begin{tabular}{rllllll}
\hline & Sex & Age onset & $\begin{array}{l}\text { Maximum } \\
\text { extent disease }\end{array}$ & $\begin{array}{l}\text { Interval onset } \\
\text { to cancer }\end{array}$ & $\begin{array}{l}\text { Age at } \\
\text { cancer }\end{array}$ & Site \\
\hline 50 & F & 23 & TC+TI & 22 & 45 & Rectum \\
135 & M & 40 & TC & 24 & 64 & Colon-splenic flexure \\
136 & F & 24 & TC & 23 & 47 & Colon-sigmoid \\
182 & F & 29 & TC+TI & 35 & 64 & Anal canal \\
468 & M & 52 & TC+TI & $13^{\star}$ & 65 & Colon-transverse mult \\
490 & F & 29 & TC & 25 & 54 & Colon-sigmoid \\
538 & M & 19 & TC & 22 & 41 & Colon-transverse \\
713 & M & 15 & TC & $12^{\star}$ & 27 & Colon-sigmoid \\
\hline
\end{tabular}

^Asymptomatic; $\mathrm{TC}=$ extensive colitis; $\mathrm{TI}=$ terminal ileum affected.
TABLE VIII Crohn's disease: cumulative proportion of patients with extensive colitis developing colorectal cancer

\begin{tabular}{lllr}
\hline Years from onset & $n$ & Cumulative \% with cancer & SEM \\
\hline $0-12$ & - & $0 \cdot 0$ & - \\
$12 \cdot 0$ & 1 & $2 \cdot 02$ & $2 \cdot 02$ \\
$12 \cdot 5$ & 1 & $4 \cdot 17$ & $2 \cdot 95$ \\
$22 \cdot 3$ & 1 & $8 \cdot 25$ & $5 \cdot 00$ \\
$22 \cdot 4$ & 1 & $12 \cdot 51$ & $6 \cdot 59$ \\
$23 \cdot 5$ & 1 & $17 \cdot 92$ & $8 \cdot 53$ \\
$24 \cdot 2$ & 1 & $23 \cdot 63$ & $10 \cdot 27$ \\
$25 \cdot 02$ & 1 & $30 \cdot 53$ & $12 \cdot 37$ \\
\hline
\end{tabular}

years from onset is $30.5 \%$ ( $95 \%$ CI 3.5 to $43 \cdot 8$ ) (Table VIII).

\section{Discussion}

\section{CASE REPORTS}

The numerous case reports and series of patients with Crohn's disease complicated by colorectal cancer all suggest an association, but only statistically based studies can estimate the significance and extent of that association.

\section{BIASES}

The cohort assembled for this study has eliminated all the known biases in a hospital based patient series. The advantages of using a hospital based series are that a large cohort can be assembled and followed up for a sufficient length of time to determine the malignant potential of Crohn's disease.

\section{SAMPLE SIZE}

Ideally the sample size might have been larger, but because this is a hospital based series from a referral centre, the proportion of patients with extensive colitis (who are particularly at risk of developing colorectal cancer) is much greater than a population based group. Thus in this series 125 of 281 patients with Crohn's disease had extensive colitis.

\section{DURATION OF FOLLOW UP}

The patients included in this study were first seen between 1945-1975 and followed up until 31 December 1991, so that the minimum follow up is 16 years and the mean follow up more than 20 years.

YOUNG AGE AT ONSET

The relation of the colorectal cancer risk with young age at onset of the underlying Crohn's disease was first noted by Weedon et al 1973. ${ }^{5}$ All patients in this study were less than 21 years of age at onset of their Crohn's disease and in this highly selective group there was a 20 -fold excess risk of developing colorectal cancer. They noted that the risk would be even higher when the estimate was restricted to patients with colonic disease alone. All eight patients in the series developing colorectal cancer had extensive or total colonic disease.

Only patients more than 15 years of age at the onset of their Crohn's disease were included in our study. In the patients less than 25 years of 
age at onset, however, the excess risk was 13.3fold and rose to $57 \cdot 2$-fold if the estimate was restricted to patients with extensive colitis.

Our findings are similar to the estimates reported in the population based series by Ekbom et al.$^{8}$ Our overall excess risk of 3.4-fold is similar to their $2 \cdot 5$-fold excess risk. The $13 \cdot 3$ fold excess risk in our series of patients less than 25 years of age at onset is similar to the 20.9-fold risk reported by Ekbom in patients with Crohn's disease affecting the colon and diagnosed before 30 years of age. ${ }^{8}$ They did not calculate the excess risk for patients with extensive or total Crohn's disease.

Thus all three series support the finding that young age at onset of Crohn's disease is an important risk factor in the subsequent development of colorectal cancer.

\section{EXTENT AND SITE OF DISEASE}

The published series ${ }^{78} 12$ when combined include 81 patients with colorectal cancer of whom 75 had evidence of colonic Crohn's disease. Among the patients where the extent of the colonic Crohn's disease was recorded, 41 of 56 colorectal cancers were associated with extensive or total colonic Crohn's disease.

Our study has confirmed that colorectal cancers complicating Crohn's disease usually develop at the site of macroscopic Crohn's disease and that nearly all such patients have large intestinal disease. All our patients with colorectal cancer had either extensive or total colonic Crohn's disease. We could quantify that there was a 18.2-fold excess for such patients with extensive colitis. Young age at onset and extensive colitis gave the highest relative risk of all at $57 \cdot 2$-fold.

\section{DURATION OF DISEASE}

There is evidence that duration of disease is a risk factor, but the risk seems to start shortly after the onset of the underlying Crohn's disease, rather than after a latent interval of some 8-10 years, which occurs in patients with ulcerative colitis.

In the selected series of young patients reported by Weedon et al, ${ }^{5}$ the colorectal cancer risk was $0.3 \%$ at 10 years and $2 \cdot 8 \%$ at 20 years from the date of onset of Crohn's disease symptoms. In the series reported by Ekbom et al, the duration of underlying Crohn's disease did not influence the colorectal cancer risk $(<10$ years, fivefold, 10-19 years twofold, and over 20 years $3 \cdot 2$-fold risk). The series was not analysed by extent of colitis.

In our own study the cumulative risk among patients with extensive colitis increased to around $30 \%$ at 25 years from onset of their Crohn's disease, but because of the comparatively small numbers, the confidence intervals are wide.

The case reports and series of patients with colorectal cancer complicating Crohn's disease also supports a relation between duration of underlying Crohn's disease and the risk of developing carcinoma. In the series of 25 patients reported by Stahl, ${ }^{4}$ the mean interval from diagnosis of Crohn's disease to the diagno- sis of cancer was $18 \cdot 5$ years (range $0-32$ years). Hamilton $e t a l^{2}$ also noted a relation to duration of underlying Crohn's disease, but two of their patients presented with carcinoma of the colon and Crohn's disease simultaneously. Some patients with Crohn's disease could be mildly symptomatic for many years before developing symptoms severe enough to warrant further investigation and thus diagnosis.

\section{AGE AT ONSET OF CANCER}

Nearly all series have shown that colorectal cancer complicating Crohn's disease occurs more often in the younger age groups than that of colorectal cancer arising in the general population de novo.

Kyle and Ewen, ${ }^{3}$ identified two distinct groups. Seven of their patients were under 55 years of age when Crohn's symptoms started. The mean interval in this group from onset of Crohn's disease to cancer was 21 years. In the second group, six patients aged 55-78 years when Crohn's disease was diagnosed, developed colorectal cancer with a mean interval from diagnosis of Crohn's disease to cancer of 19.6 months (one month to three years). The author suggests that in the second group the number of the carcinomas was spontaneous and would probably have occurred by chance.

The number of patients with older age at onset Crohn's disease is small by definition. There were none in the series of Weedon et al..$^{5}$ The number of patients in the series by Ekbom et al ${ }^{8}$ over 55 years was not stated.

In our own series only 69 patients were over 40 years of age at onset of their Crohn's disease, of whom only 21 had extensive colitis.

The studies where no association between colorectal cancer and Crohn's disease was seen, could be explained by a comparatively short follow up,' a large number of patients with Crohn's colitis undergoing panproctocolectomy or colectomy, ${ }^{10}$ and a comparatively small number of patients under review for a short period of follow up. ${ }^{11}$ It could be that there are national or regional differences in the colorectal cancer risk in Crohn's disease.

We have shown in this study that there is a statistically significant excess risk of developing colorectal cancer in patients who develop their Crohn's disease at a young age of onset (less than 30 years of age) and that the risk is increased in patients with extensive colonic involvement and that there is a relation with increasing duration of disease, although occasionally colorectal cancer is seen within a few years of diagnosis of the underlying Crohn's disease. The absolute numbers of patients developing colorectal cancer as a complication of Crohn's disease is small, probably because patients with extensive Crohn's colitis usually have persistent or recurrent symptoms that warrant surgical resection within the first few years after diagnosis of their Crohn's disease, thus eliminating the colorectal cancer risk.

The observed excess risks seen in this study therefore only apply to a comparatively small proportion of patients with Crohn's disease. Using this hospital based series of patients with 
Crohn's disease and eliminating all the known biases that might affect a hospital referral series, it should now be possible to compare the colorectal cancer risk in patients with Crohn's disease and ulcerative colitis.

The authors are grateful for the generous financial support from the Cancer Research Campaign and the National Association for Colitis and Crohn's Disease.

1 Lewis D, Zinkin MD, Bradwein C. Adenocarcinoma in Crohn's colitis. Dis Colon Rectum 1980; 23: 115-7.

2 Hamilton SR. Colorectal carcinoma in patients with Crohn's disease. Gastroenterology 1985; 89: 398-407.

3 Kyle J, Stanley WB. Two types of colorectal carcinoma in Crohn's disease. Ann R Coll Surg Engl 1992; 74: 387-90.

4 Stahl TJ, Schoetz DJ Jr, Roberts PL, et al. Crohn's disease and carcinoma: increasing justification for surveillance? Dis Colon Rectum 1992; 35: 850-6.

5 Weedon DD, Shorter RG, Ilstrup DM, et al. Crohn's disease and cancer. N Engl F Med 1973; 289: 1099-103.

6 Greenstein AJ, Sachar DB. Cancer in Crohn's disease. In: Allan RN, Keighley MRB, Alexander-Williams J, Hawkins $\mathrm{CF}$, eds. Inflammatory bowel disease. Edinburgh: Churchill Livingstone, 1983: 332-7.
7 Greenstein AJ, Sachar DB, Smith H, et al. A comparison of cancer risk in Crohn's disease and ulcerative colitis. Cancer 1981; 48: 2742-5.

8 Ekbom A, Helmick C, Zack M, Hans-Olov A. Increased risk of large bowel cancer in Crohn's disease with colonic involvement. Lancet 1990; 336: 357-9.

9 Binder V, Hendriksen C, Kreiner S. Prognosis in Crohn's disease - based on results from a regional patient group from the county of Copenhagen. Gut 1985; 26: 146-50.

10 Kvist $N$, Jacobsen $O$, Norgaard $P$, et al. Malignancy in Crohn's disease. Scand $\mathcal{f}$ Gastroenterol 1986; 21: 82-6.

11 Gollop JH, Phillips SF, Melton L III, Zinsmeister AR. Epidemiologic aspects of Crohn's disease. Gut 1988; 29: 49-

12 Gyde SN, Prior P, McCartney JC, Thompson H, Waterhouse JAH, Allan RN. Malignancy in Crohn's disease. Gut 1980; 21: $1024-9$.

13 Gyde SN, Prior P, Allan RN, Stevens A, Jewell DP, Truelove SC, et al. Colorectal cancer in ulcerative colitis: a cohort study of primary referrals from three centres. Gut 1988; 29 : 206-17.

14 Coleman M, Douglas A, Hermon C, Peto J. Cohort study analysis with a FORTRAN computer program. Int $\mathcal{F}$ Epidemiol $1986 ; 15: 134-7$

15 Rothnam KT, Boice JD Jr. In: Enidemiologic analysis with a programmable calculator. NIH Publication No 70-1649. programmable calculator. NIH Publication No 70-1649. 